This report was prepared as an account of work sponsored by an agency of the United States Government. Neither the United States Government nor any agency thereof, nor any of their employees, makes any warranty, express or implied, or assumes any legal liability or responsibility for the accuracy, completeness, or usefulness of any information, apparatus, product, or ence herein to any specific commercial product manufacturer, or otherwise does not necessarily constitute or imply its endorsement, recommendation, or favoring by the United States Government or any agency thereof. The views and opinions of authors expressed herein do not necessarily state or reflect those of the United States Government or any agency thereof.

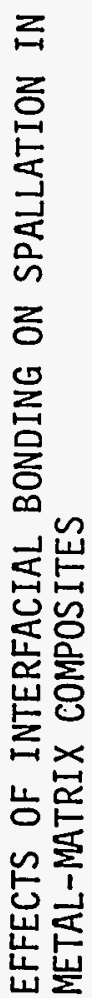
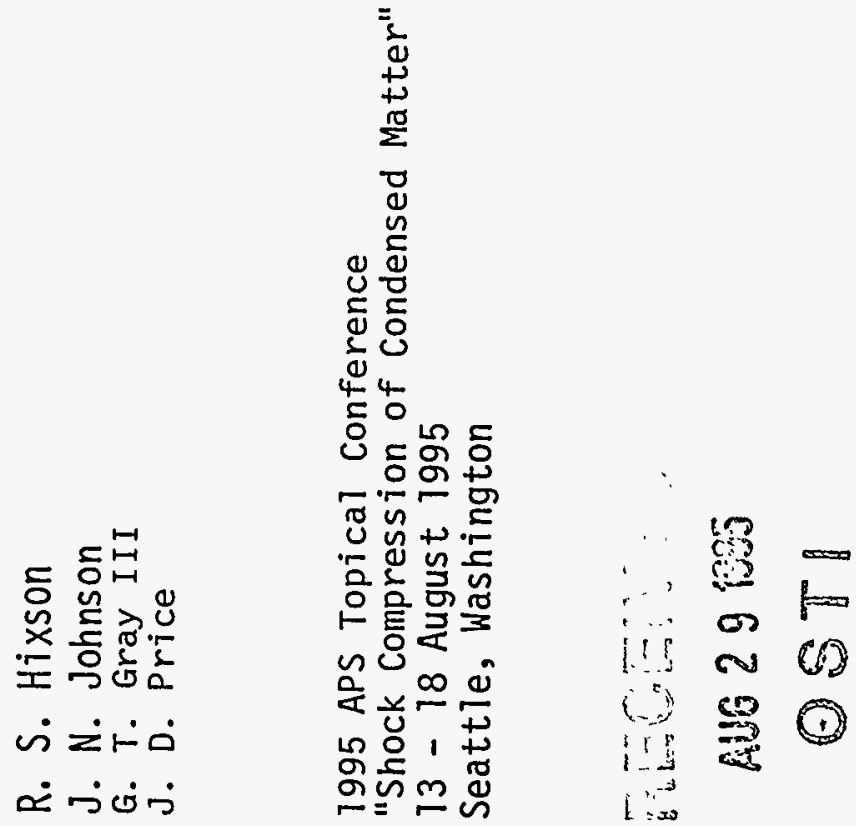

$\stackrel{\ddot{H}}{\stackrel{\underline{F}}{F}}$

2

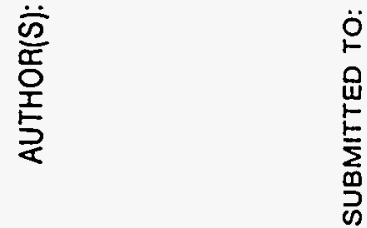




\section{DISCLAIMER}

Portions of this document may be illegible in electronic image products. Images are produced from the best available original document. 


\title{
EFFECTS OF INTERFACIAL BONDING ON SPALLATION IN METAL-MATRIX COMPOSITES
}

\author{
R.S. Hixson, J.N. Johnson, G.T. Gray III, and J.D. Price \\ Los Alamos National Laboratory, Los Alamos, NM, 87545, USA
}

Two metal-matrix composite systems are studied to determine the influence of inclusions on the spallation strength in plate-impact experiments. The first is an aluminum/ceramic system with several volume fractions of ceramic inclusion, and the second is a copper/niobium composite consisting of 15 vol. \% niobium particles embedded in the copper matrix. Plate-impact experiments produce peak compressive stresses of $\sim 5 \mathrm{GPa}$ in the aluminum/ceramic system and $\sim 10 \mathrm{GPa}$ in the copper/niobium system. The characteristic code CHARADE is used to calculate detailed compression-release profiles in the composite systems, thus accurately quantifying the wave-evolution occurring between the spall plane and the particle velocity (VISAR) measurement at the rear free surface. The aluminum/ceramic system exhibits a strong dependence of the spall strength on inclusion concentration and morphology. In the case of the copper/niobium system, the spall strength remains essentially unchanged by the presence of $15 \mathrm{vol}$. \% niobium particles embedded in the copper matrix.

\section{INTRODUCTION}

Composite materials are currently being proposed for use in a wide variety of applications. Some of these applications involve subjecting such materials to impact and dynamic tension. In this paper we present data obtained using shock compression techniques to spall several metal-matrix composites. These include three volume fractions of Al/ceramic materials and one metal-matrix/metal composite, $\mathrm{Cu} / \mathrm{Nb}$. Measurements are complemented by calculations performed with the characteristic code CHARADE (1), which gives the dynamic tensile (spall) strength at a point within the impacted sample.

\section{EXPERIMENT}

Experiments were performed on several materials. The metal-matrix/ceramic composites were of two kinds. The first material was 6061-T6 aluminum with embedded spherical particles of mullite $\left(3 \mathrm{Al}_{2} \mathrm{O}_{3}, 2 \mathrm{SiO}_{2}\right)$. This material has a density of $2.840 \mathrm{gm} / \mathrm{cm}^{3}$ and a volume fraction of mullite of approximately $20 \%$. The other metal- matrix/ceramic composites (2) were 6061-T6 aluminum with angular alumina $\left(\mathrm{Al}_{2} \mathrm{O}_{3}\right)$ inclusions at two volume fractions ( 8 and 17\%). The material chosen for the metal-matrix/metal composite was $\mathrm{Cu} / \mathrm{Nb}$. This material consists of a $\mathrm{Cu}$ matrix with inclusions of $\mathrm{Nb}$ at a volume fraction of $15 \%$; a metallograph of this material is shown in Figure 1.

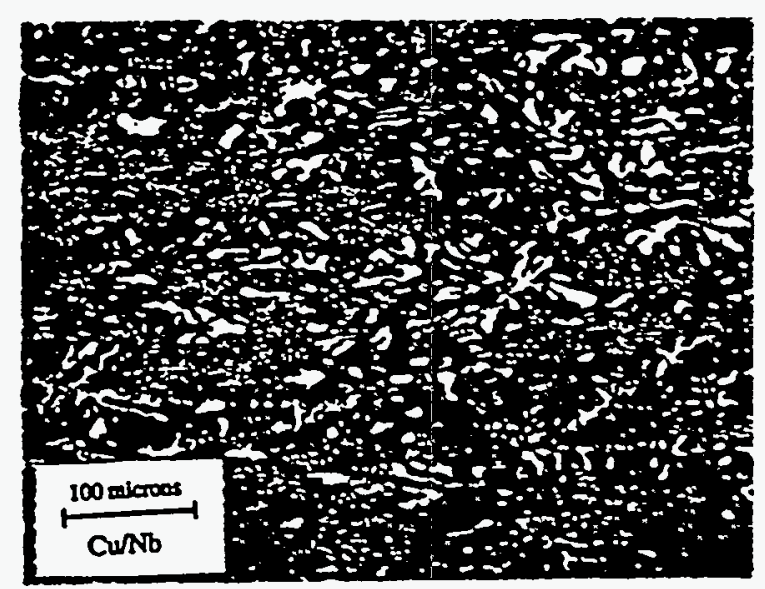

FIGURE 1. Metallography of $\mathrm{Cu} / \mathrm{Nb}$ composite. 
TABLE 1. Summary of Spallation Experiments.

\begin{tabular}{|c|c|c|c|c|c|}
\hline Experiment & $\begin{array}{l}\text { Projectile } \\
\text { Velocity }(\mathrm{m} / \mathrm{s})\end{array}$ & $\begin{array}{l}\text { Targ.(mm)/ } \\
\text { Imp.(mm) }\end{array}$ & $\begin{array}{l}\text { Vol. \% } \\
\text { Inclusion }\end{array}$ & $\begin{array}{l}\text { Spall Str. } \\
\text { (GPa) }\end{array}$ & $\begin{array}{c}\text { Inclusion } \\
\text { diam/marphology }\end{array}$ \\
\hline $\begin{array}{l}\text { A1959 } \\
\text { (6061-T6) }\end{array}$ & $550(Q t z)$ & $3.886 / 2.699$ & 0 & 2.8 & N/A \\
\hline Com3 & $506(\mathrm{Q} t z)$ & $3.744 / 2.840$ & 20 & 1.9 & $25-50 \mu \mathrm{m} /$ spherical \\
\hline Durl & $508(Q t z)$ & $3.978 / 2.803$ & 8 & 2.0 & $8-10 \mu \mathrm{m} / a n g u l a r$ \\
\hline Als3_3 & $502(Q t z)$ & $3.820 / 2.918$ & 17 & 1.1 & $20-25 \mu \mathrm{m} /$ angular \\
\hline $\begin{array}{l}\text { Cus2_10 } \\
\text { (OFE Cu) }\end{array}$ & 499 (Sapphire) & $4.016 / 2.817$ & 0 & 3.5 & N/A \\
\hline Cunb3 & 505 (Sapphire) & $4.005 / 2.993$ & 15 & 3.5 & $20-25 \mu \mathrm{m} /$ oblong \\
\hline
\end{tabular}

Measured ultrasonic velocities for the $\mathrm{Cu} / \mathrm{Nb}$ material were $C_{l}=4.814 \mathrm{~mm} / \mu \mathrm{s}$ and $C_{s}=2.199$ $\mathrm{mm} / \mu \mathrm{s}$. Density of the $\mathrm{Cu} / \mathrm{Nb}$ material was measured by an immersion technique to be 8.88 $\mathrm{gm} / \mathrm{cm}^{3}$ and the density for pure Cu was taken to be $8.93 \mathrm{gm} / \mathrm{cm}^{3}$. Spall measurements were also performed on 6061-T6 aluminum and OFE copper to determine the spall strength of the matrix material alone; for these nominal impact conditions, the spall strength of the aluminum alloy is $2.8 \mathrm{GPa}$ and that of copper is $3.5 \mathrm{GPa}$.

Shock-compression experiments were performed at two gas-gun facilities, one with a 50-mm bore and one with a 72-mm bore. Impactors used for the Al-based composites were Z-cut quartz glued to PMMA backing pieces and inlet into the nose of the projectile. Z-cut quartz was chosen because it responds elastically in the pressure range of these experiments. For the Cu-based composites Z-cut sapphire impactors were used. Various thicknesses of impactors were chosen depending upon experimental requirements. Experimental configurations were calculated using the MACRAME computer code (3). Edge-effect calculations were also carried out for each experiment to ensure one-dimensional flow for the entire time of interest. A summary of spallation (only) experiments is given in Table I.
Impact response was measured using timeresolved velocity interferometry, with a push/pull VISAR (4). This diagnostic system is capable of nanosecond level resolution, and yields particle velocity histories with less than $1 \%$ uncertainty. Particle-velocity data were taken at a free surface for spall experiments, and at a target/window interface for wave-profile experiments (not presented here).

$\mathrm{LiF}(100)$ windows were used for the Al-based composites and sapphire (Z-cut) for the Cu-based materials because of the close shock impedence match. For window experiments a thin $(13 \mu \mathrm{m})$ aluminum shim was placed between the window and the target. We were able to perform free-surface (spall) experiments with no foil by slightly defocusing the VISAR laser spot.

\section{Calculation}

Analysis is carried out with the rate-dependent characteristic code CHARADE (1). The rate dependence in these calculations is contained in the micromechanical model of plastic flow and not in the fracture process. A simple tensile fracture model is used for spallation. The benefit of using a sophisticated rate-dependent elastic-viscoplastic model for compression and release comes from the 


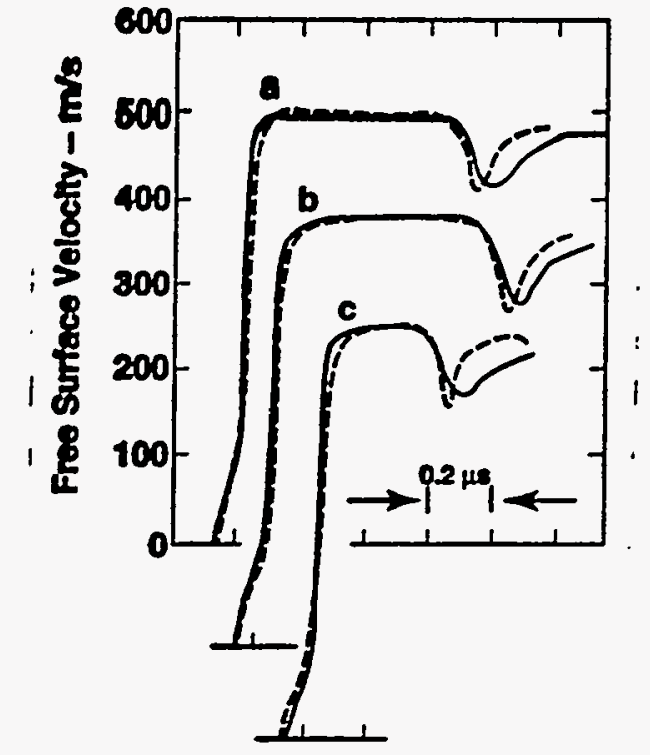

FIGURE 2. Spall signals for $A$ //ceramic composites; (a) Com3, (b) Dur1, and (c) Als3_3.

ability to accurately calculate the evolution of waves that travel from the spall plane (where the fracture occurs) to the free surface (where the measurement is made). For simple materials that are nearly linear elastic, the calculation of the spall strength can be carried out analytically. For complex elastic-plastic solids this is difficult and numerical methods are more useful.

CHARADE contains advanced models of ratedependent elastic-plastic flow as well as micromechanical models of quasielastic release from the shocked state (5). This sophistication gives some assurance that the evolution of the spall signal will be faithfully simulated in the numerical calculation. These data and calculations (not shown) then provide necessary rate-dependent constitutive properties for the materials studied here.

Elastic moduli and equations of state of the composite materials are obtained from mixture thearies described in reference (2).

\section{RESULTS}

In Figure 2 we show the spall results for the $\mathrm{Al} /$ ceramic composites (2). The spall strength of the composites may readily be seen to vary with volume fraction of ceramic reinforcement, and with shape. The presence of the alumina particles also changes the nature of the spall 'pullback' signal indicating sluggish behavior as compared to the 6061-T6 Al result: Figure 3. It is clear by comparing the results,

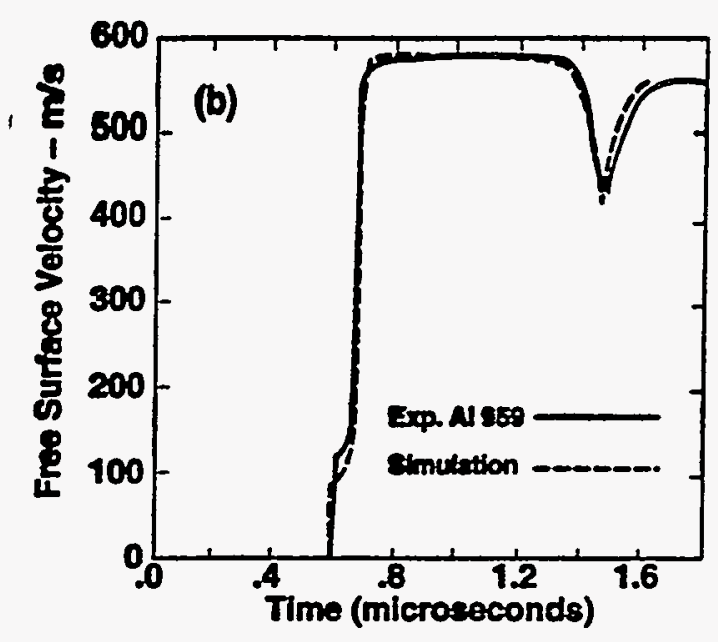

FIGURE 3. Spall signal for 6061-T6 Al.

with and without ceramic reinforcement, that the spall strength in the composites are all lower than that in 6061-T6 aluminum (Table 1).

Spall results for the $\mathrm{Cu} / \mathrm{Nb}$ composite and $\mathrm{OFE}$ $\mathrm{Cu}$ are shown in Figures 4 and 5. To within experimental uncertainties there is no difference in the spall behavior of these two materials, a somewhat surprising result.

One unusual feature observed in the spallation properties of the $\mathrm{Cu} / \mathrm{Nb}$ composite is the small secondary spall resistance observed immediately following the minimum in the particle-velocity/time record of Figure 4. There is considerable structure in this region; it has the same qualitative features as found in the spallation of tantalum (6).

\section{DISCUSSION}

Wave-profile and spall experiments have been performed on two very different metal-matrix composites. The systems studied here were a metalmatrix/metal $(\mathrm{Cu} / \mathrm{Nb})$, and several metalmatrix/ceramic materials ( $\mathrm{Al} / \mathrm{Al}_{2} \mathrm{O}_{3}$ and $\mathrm{Al} /$ mullite). Results indicate that the $\mathrm{Cu} / \mathrm{Nb}$ material is essentially indistinguishable from pure OFE $\mathrm{Cu}$ in wave-profile and spall-signal measurements. The spall strength of this material is $3.5 \mathrm{GPa}$.

Results for the $\mathrm{Al} / \mathrm{Al}_{2} \mathrm{O}_{3}$ composites show that there is a considerable difference in spall behavior of these composites in comparison to 6061-T6 Al. The spall strength for 6061-T6 aluminum is 2.8 


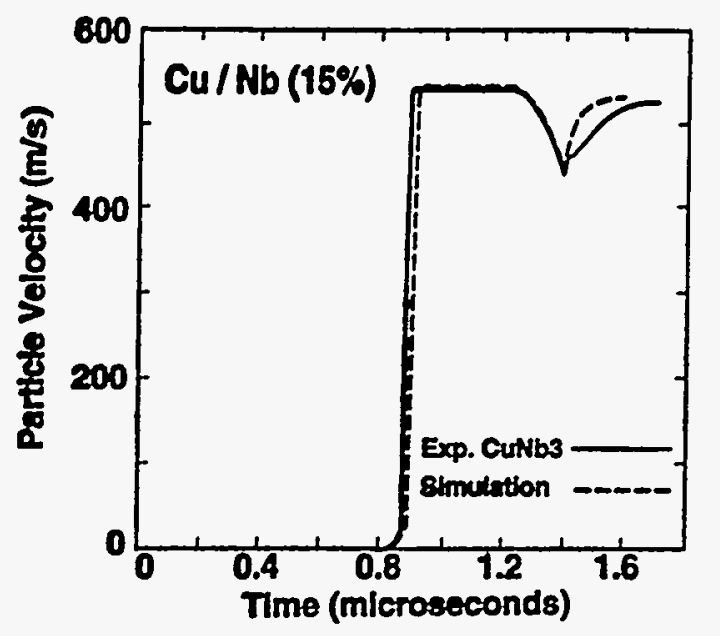

FIGURE 4. Spall signal for $\mathrm{Cu} / \mathrm{Nb}$ composite.

$\mathrm{GPa}$, while that for the aluminum/ceramic composites varies from 1.1 to $2.0 \mathrm{GPa}$ depending on volume fraction of ceramic reinforcement and particle morphology. This complements the lowstrain-rate results of Song, et al (7). The presence of the ceramic inclusions apparently allows complex interfacial bonding properties to contribute strongly to the material strength in tension. Our experiments show that not only does volume fraction of the ceramic reinforcement affect spall strength, but also particle shape plays a major role.

In the case of aluminum/alumina it might be suspected that the interfacial bond itself is weak; simply because of the difference between the electronic structure of metals and ceramics. However, it is believed that this bond is fairly strong and that the weakness comes from ductile failure in the metal (aluminum) adjacent to the interface between these two materials. The presence of significant elastic moduli differences contributes to substantial hydrostatic tension and causes voids to grow in the vicinity of the interface.

The equations of state of the $\mathrm{Cu} / \mathrm{Nb}$ and Al/ceramic composites are calculated from simple mixture theory. Measurement of shock velocity as a function of shock amplitude would help to define the Hugoniots of these materials. Other work that would be of interest is the impact and spallation of materials which contain continuous reinforcement in the form of fine wires, for example. Experiments on these types of composites are described elsewhere in the conference (8).

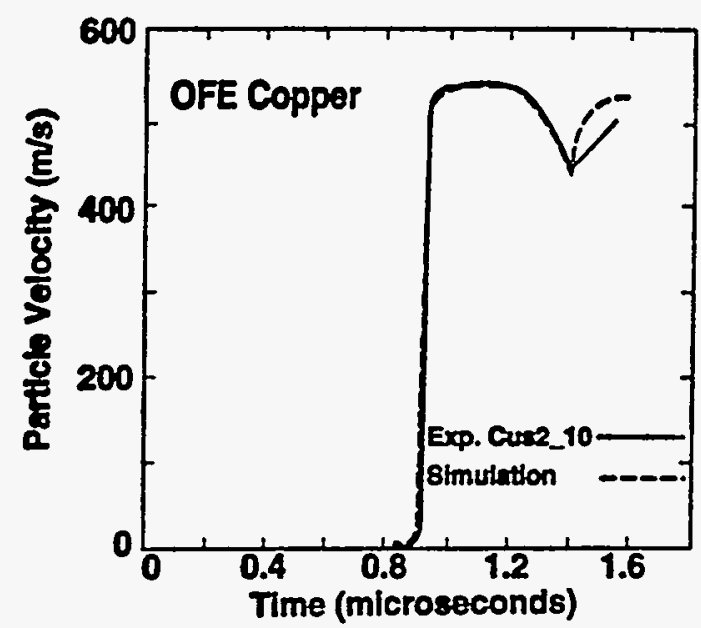

FIGURE 5. Spall signal for OFE copper.

\section{REFERENCES}

1. Johnson, J.N. and Tonks, D.L., "CHARADE: A Characteristic Code for Calculating RateDependent Response," Los Alamos National Laboratory Report LA-11993-MS, Jan. (1991).

2. Johnson, J.N., Hixson, R.S., and Gray III, G.T., "Shock-Wave Compression and Release of Aluminum/Ceramic Composites," J. Appl. Phys. 76, 5706-5718 (1994).

3. Fritz, J., Personal Communication (1994).

4. Hemsing, W.F., "Velocity Sensing Interferometer (VISAR) Modification," Rev. Sci. Instrum. 50, 73-78 (1979).

S. Johnson, J.N., Hixson, R.S., Gray III, G.T., and Morris, C.E., "Quasielastic Release in ShockCompressed Solids," J. Appl. Phys. 72, 429-441 (1992).

6. Johnson, J.N., Hixson, R.S., Tonks, D.L. and Zurek, A.K., "Rate-Dependent Spallation Properties of Tantalum," this conference.

7. Song, et al.

8. Gray III, G.T., Hixson, R.S., and Johnson, J.N., "Dyaamic Deformation and Fracture Response of - 6061Al - 50 vol.\% $\mathrm{Al}_{2} \mathrm{O}_{3}$ Continuous Reinforced Fiber Composite," this conference. 